УДК 628.542 .61

${ }^{[0000-0002-9795-7110]}$ И. В. Косогина ${ }^{\mathbf{1}}$, к.т.н., доцент, e-mail: kosoginairyna@gmail.com

${ }^{[0000-0003-0693-865 Х] ~ Н . ~ А . ~ К л и м е н к о ~}{ }^{2}$, д.х.н., профессор,

Л. А. Савчина ${ }^{2}$, к.х.н., стариий научный сотрудник,

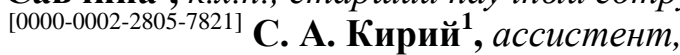

${ }^{[0000-0002-8775-2744]}$ И. М. Астрелин ${ }^{1}$, д.m.н., профессор,

Е. А. Самсони-Тодорова ${ }^{2}$, к.т.н., научный сотрудник

${ }^{1}$ Национальный технический университет Украины «Киевский политехнический институт имени Игоря Сикорского», пр-т Победы, 37, г. Киев, 03056, Украина

${ }^{2}$ Институт коллоидной химии воды им. А. В. Думанского НАН Украины,

б-р Академика Вернадского, 42, г. Киев, 03142, Украина

\title{
СОРБЦИЯ СУЛЬФАНИЛОВОЙ КИСЛОТЫ И ИОНОВ МЕДИ АКТИВИРОВАННЫМ УГЛЕМ, МОДИФИЦИРОВАННЫМ ОКСИДАМИ МЕТАЛЛОВ
}

Исследован процесс сорбиии сульфаниловой кислоты и ионов меди модифицированным и немодифицированным активированным углем Filtrasorb 300 (AУ F300). Определены структурно-сорбиионные характеристики исследованных материалов: статическая обменная катионная и анионная емкости и количество поверхностных групп (карбоксильные, лактонные, фенольные). Показан положительный эффект модификации активированного угля оксидами металлов, полученными в результате кислотно-термической обработки «красного шлама». Наличие отрицательно заряженных активных иентров на поверхности модифицированного активированного угля позволяет повысить на $59 \%$ величину адсорбции сульфаниловой кислоть за счет взаимодействия поверхности материала с аминогруппой кислоты при отсутствии ионов меди в растворе, что на $24 \%$ больше, чем на АB F300. Одновременное присутствие ионов меди и сульфаниловой кислоты уменьшает их адсорбиию на модифицированном сорбенте в результате блокировки активных групп и снижения электростатического взаимодействия. Установлено, что при низких значениях рН среды имеет место, вероятнее всего, комплексообразование ионов меди с молекулой сульфаниловой кислоты по группе $-\mathrm{NH}_{2}$, при условии значительного превышения содержания ионов меди в растворе. Подтверждена возможность использования модифищированного оксидами металлов активированного угля марки Filtrasorb 300 для извлечения из воды сульфаниловой кислоты и ионов меди.

Ключевые слова: сорбчия, модифичированный активированный уголь, структурносорбиионные характеристики, сульфаниловая кислота, ионы меди, водоочистка.

Введение. Традиционные технологии очистки воды от мультикомпонентных загрязнителей включают химическое осаждение, окисление повышенной эффективности, биологическую очистку, мембранное фильтрование и адсорбцию [1-2]. Среди этих методов адсорбция как наиболее эффективная и экономичная технология имеет широкое применение для удаления многочисленных загрязнений в практике очистки сточных вод. Обзор последних публикаций показывает, что одновременному удалению из воды органических загрязнений и ионов тяжелых металлов уделяется много внимания. Основной акцент в этих публикациях сделан на использовании в качестве сорбентов специально синтезированных хелатообразующих и ионообменных смол.
В ряде случаев при одновременной или последовательной адсорбции проявлялся эффект синергизма удаления органического загрязнения и ионов тяжелых металлов [3]. Отмечено значительное усиление адсорбции тетрациклина в присутствии $\mathrm{Cu}^{2+}$ вследствие образования третичного поверхностного комплекса [сорбент - $\mathrm{Cu}^{2+}$ - тетрациклин]. Образование этого комплекса усилило также адсорбцию и ионов $\mathrm{Cu}^{2+}$. В качестве сорбента был использован бифункциональный сорбент, обладающий катионообменной емкостью и поверхностью $394 \mathrm{~m}^{2} / \Gamma$. Увеличение $\mathrm{pH}$ приводило к увеличению сорбции $\mathrm{Cu}^{2+}$, в то время как адсорбированное количество тетрациклина увеличивалось лишь в диапазоне $\mathrm{pH}$ от 2 до 3 и уменьшалось при дальнейшем повышении $\mathrm{pH}$.

() И. В. Косогина, Н. А. Клименко, Л. А. Савчина, С. А. Кирий, И. М. Астрелин, Е. А. Самсони-Тодорова, 2019 DOI: $10.24025 / 2306-4412.3 .2019 .178235$ 
Однако, как показано в [4], на другом сорбенте - хелатообразующей смоле (R-AC), содержащей бифункциональные группы (амино- и карбоксигруппы), адсорбция тетрациклина увеличивалась в присутствии $\mathrm{Cu}^{2+}$ в 13 раз по сравнению с системой без меди, в то время как извлечение $\mathrm{Cu}^{2+}$ иногда (редко) уменьшалось в присутствии тетрациклина. Это, по мнению авторов статьи, обусловлено разрушением комплексных связей, которые включали комплексы [Cu - тетрациклин] и [смола - Cu], связывающих тетрациклин.

Высокий эффект совместного удаления $\mathrm{Cu}^{2+}$ и $n$-нитрофенола был получен на синтезированной полиаминной хелатообразующей смоле. Показано, что $n$-нитрофенол адсорбировался как на гидрофобных, так и на гидрофильных адсорбционных центрах, в то время как $\mathrm{Cu}^{2+}$ взаимодействовал только с гидрофильными аминогруппами. Адсорбция nнитрофенола подавлялась в присутствии $\mathrm{Cu}^{2+}$ вследствие селективной избирательности и конкуренции. С другой стороны, присутствие $n$-нитрофенола усиливало адсорбцию $\mathrm{Cu}^{2+}$ более, чем на $7 \%$, что было связано с размещением $n$-нитрофенола на гидрофобной поверхности. В этом случае гидроксильные группы $n$-нитрофенола, обращенные в объем раствора, обеспечивали новые места для координации с $\mathrm{Cu}^{2+}[5]$.

Эффект синергизма при адсорбции тетрациклина и меди получен при использовании мезопористого силикагеля, функционализированного диаминогруппами и $\mathrm{Fe}(\mathrm{III})$. Увеличение адсорбции тетрациклина (ТЦ) и $\mathrm{Cu}(\mathrm{II})$ исследователи объяснили образованием комплекса ТЦ - $\mathrm{Cu}$ (II) с более сильным сродством адсорбента к комплексу, чем к ТЦ и $\mathrm{Cu}$ (II) отдельно [5].

При адсорбции фенола и ионов $\mathrm{Cu}^{2+}$ из смешанного раствора методом фотоэлектронной спектроскопии было установлено, что ионы меди были первоначально адсорбированы на поверхности пористого сорбента (модифицированный карбоновой кислотой полицидильный метакрилат). Затем обогащенная ионами поверхность раздела была более выгодной для адсорбции фенола, т.о. ионы меди играли важную роль в усилении адсорбционной способности сорбента по фенолу [6].

При исследовании совместной адсорбции атенолола и меди на катионообменной смоле было установлено, что в смешанном растворе адсорбция атенолола была подавле- на вследствие прямой конкуренции со стороны карбоксильных групп за адсорбционные места для $\mathrm{Cu}^{2+}$. В то же время адсорбция $\mathrm{Cu}^{2+}$ усиливалась вследствие образования поверхностных комплексов. Как амино-, так и гидроксильные группы адсорбированного атенолола могут образовывать поверхностные комплексы с $\mathrm{Cu}^{2+}$ [7].

Применение АУ для очистки природных и сточных вод обусловлено высокой избирательностью адсорбции органических соединений углем. Однако, в сточных водах различного происхождения одновременно с органикой возможно наличие ионов цветных металлов, которые могут конкурировать с органическими загрязнениями, большая часть которых представляет собой слабые электролиты.

Большинство имеющихся на рынке активированных углей (АУ) являются слабокислотными или слабоосновными с небольшой общей обменной емкостью $(0,6-0,8$ мг-экв/г) и невысоким содержанием поверхностных групп. Для обеспечения возможности извлечения из воды ионов цветных металлов и диссоциирующих органических электролитов целесообразно использовать модифицирование АУ с целью увеличения обменной емкости.

В соответствии с [8] техника модификации АУ имеет три основных направления: химическая, физическая и биологическая модификации. Химическая активация в ряде случаев приводит к образованию функциональных групп на поверхности угля, которые обусловливают извлечение ионов металлов из воды [9]. В результате модифицирования АУ оксидами железа увеличивается основность поверхности сорбента и повышается эффективность удаления из воды производных бензола [10].

Влияние кислородсодержащих поверхностных функциональных групп активированного угля на адсорбцию из растворов систематически исследовано только для адсорбции электролитов, т.е., когда причиной адсорбции являются ионообменные или электрохимические процессы. Практически отсутствуют работы, посвященные исследованию степени участия поверхностных групп при одновременной адсорбции органических слабых электролитов и ионов металлов на модифицированных углеродных сорбентах.

Таким образом, краткий анализ приведенных работ по одновременному извлечению из воды органических веществ и ионов

(С И. В. Косогина, Н. А. Клименко, Л. А. Савчина, С. А. Кирий, И. М. Астрелин, Е. А. Самсони-Тодорова, 2019 DOI: $10.24025 / 2306-4412.3 .2019 .178235$ 
цветных металлов показывает, что основное внимание уделено использованию специфических функционализированных сорбентов. При этом при совместном присутствии органических соединений и ионов тяжелых металлов может иметь место как синергический эффект, так и подавление сорбции одного из компонентов. Вопросам использования активированных углей для эффективного извлечения из воды смеси указанных примесей уделено гораздо меньше внимания. Тем не менее, в ряде работ показано, что изменение поверхности АУ путем увеличения количества поверхностных функциональных групп является приемлемым методом повышения эффективности адсорбционных свойств АУ по отношению к ионам цветных металлов [11]. Во многих работах отмечено, что введение кислородсодержащих функциональных групп значительно улучшило адсорбционную способность АУ к металлам вследствие увеличения сил электростатического взаимодействия активных центров для комплексообразования с ионами тяжелых металлов [12].

В работе [13] установлено, что модифицированный АУ проявляет хорошую адсорбционную способность при адсорбции из водных растворов как относительно органических веществ (фенола, хлороформа, пиридина, анилина), так и ионов тяжелых металлов. Селективность активированного угля по отношению к ионам металлов может быть повышена за счет его модификации оксидами металлов.

Целью работы было установить возможность использования активированного угля марки Filtrasorb 300, модифицированного оксидами металлов (F300 M), в сравнении с немодифицированным (F300 Н) для одновременного извлечения из воды органических соединений и ионов меди. В качестве модификатора был использован раствор хлоридов металлов, полученный кислотно-термической активацией отходов глиноземных производств «красный шлам».

Методика эксперимента. В качестве объекта исследования была выбрана сульфаниловая (n-аминобензойная) кислота (СК), представляющая собой внутреннюю соль, в которой аминогруппа нейтрализована остатком сульфокислоты, поэтому она не образует солей с минеральными кислотами. Кислотные свойства в сульфаниловой кислоте преобладают над основными.
Выбор в качестве объекта исследования сульфаниловой кислоты обусловлен ее широким использованием в синтезе различных красителей, при синтезе таких фармпрепаратов, как сульфаниламид, альбуцид, сульгин, сульфидин, сульфодимезин, сульфазол и др. Таким образом, выяснение специфики поведения СК при глубокой адсорбционной очистке сточных вод позволяет не только оценивать эффективность процесса сорбции СК, но и прогнозировать возможность извлечения препаратов на ее основе. Для выяснения специфики адсорбционного поведения СК на активированном угле при наличии неорганических ионов, которые могут присутствовать в сточных водах, выбраны соли меди, широко используемые при синтезе полиазокрасителей, ариламиновых красителей, азиновых красителей, прямых металлсодержащих азокрасителей и др.

В качестве исходного сорбента использовали активированный уголь Filtrasorb 300 (F $300 \mathrm{H}$ ).

Вещество $n$-хлоранилин было использовано как стандартный адсорбтив, отвечающий условиям надежной оценки удельной поверхности углеродных материалов по адсорбции из водных растворов. Ароматические кольца $n$-хлоранилина ориентированы на границе раздела фаз своей плоскостью параллельно углеродной поверхности, так как при этом наибольшее число атомов молекулы адсорбата находится на самом близком расстоянии от поверхности атомов углерода, что отвечает условию максимальной интенсивности дисперсионного взаимодействия, однако группа $\mathrm{NH}_{2}$ или, по крайней мере, протон этой группы оттянуты от плоскости вглубь жидкой фазы вследствие сохранения Н-связи с ближайшими молекулами воды. Такая ориентация молекулы $n$-хлоранилина на углеродной поверхности при адсорбции из водного раствора соответствует величине ван-дер-ваальсовой проекции молекулы на плоскость, равной 0,49 нм².

Модификацию АУ оксидами железа проводили по методике, подробно описанной в [14], с некоторыми изменениями: для пропитки угля вместо сульфата железа использовали раствор хлоридов металлов, полученный после обработки отходов глиноземных предприятий соляной кислотой (12-15\%) при температуре $100{ }^{\circ} \mathrm{C}$. Жидкая фаза после обработки отходов глиноземных предприятий соляной кислотой имеет состав, приведенный в таблице 1.

(с) И. В. Косогина, Н. А. Клименко, Л. А. Савчина, С. А. Кирий, И. М. Астрелин, Е. А. Самсони-Тодорова, 2019 DOI: $10.24025 / 2306-4412.3 .2019 .178235$ 
Таблица 1 - Состав жидкой фазы после кислотной обработки отходов глиноземных предприятий - «красного шлама» (КШ)

\begin{tabular}{|l|l|l|l|l|l|l|l|l|l|l|}
\hline Элемент & $\mathrm{Fe}$ & $\mathrm{Al}$ & $\mathrm{Ca}$ & $\mathrm{Ti}$ & $\mathrm{Si}$ & $\mathrm{Na}$ & $\mathrm{Cr}$ & $\mathrm{Zr}$ & $\mathrm{V}$ & $\mathrm{Mn}$ \\
\hline Содержание, \% & 71,25 & 19,02 & 2,58 & 2,48 & 2,33 & 0,77 & 0,55 & 0,22 & 0,15 & 0,13 \\
\hline
\end{tabular}

В состав жидкой фазы после кислотной обработки «красного шлама» входят преимущественно соли трехвалентного железа, алюминия, кальция, титана, кремния.

Структурно-сорбционные параметры угля Filtrasorb 300, модифицированного оксидами металлов (преимущественно $\mathrm{Fe}_{2} \mathrm{O}_{3}$ ) (F $300 \mathrm{M}), \quad$ оценивали по адсорбции $n$-хлоранилина. Сравнительные данные измерений представлены в таблице 2.

Статические катионо- (КСОЕ) и анионообменную (АСОЕ) емкости и количество поверхностных групп сорбентов определяли по методу Бёма, а точку нулевого заряда (ТН3) - в соответствии с методикой, описанной в [15] (таблица 3 ).

Таблица 2 - Сравнительные данные изменения структурно-сорбционных параметров модифицированного угля Filtrasorb 300 по адсорбции $\boldsymbol{n}$-хлоранилина

\begin{tabular}{|l|c|c|c|}
\hline \multicolumn{1}{|c|}{ Сорбент } & $\mathrm{a}_{\infty}$, моль $/ \Gamma$ & $\mathrm{V}_{\mathrm{a}}, \mathrm{cm}^{3} / \Gamma$ & $\mathrm{S}_{\mathrm{a}}{ }^{*}, \mathrm{~m}^{2} / \Gamma$ \\
\hline F 300 H & 4,3 & 0,47 & 1270 \\
\hline F 300 M & 4,6 & 0,48 & 1195 \\
\hline
\end{tabular}

$\mathrm{S}_{\mathrm{a}}{ }^{*}$ - эффективная удельная поверхность сорбента по адсорбции $n$-хлоранилина.

Таблица 3 - Химия поверхности немодифицированного и модифицированного углей Filtrasorb 300

\begin{tabular}{|c|c|c|c|c|c|c|}
\hline \multirow{3}{*}{ Сорбент } & \multirow{2}{*}{ КСOE } & \multirow{2}{*}{$\mathrm{ACOE}$} & \multicolumn{3}{|c|}{ Содержание поверхностных групп } & \multirow{2}{*}{$\begin{array}{l}\text { Величина } \\
\text { рН ТН3 }\end{array}$} \\
\hline & & & карбоксильные & лактонные & фенольные & \\
\hline & \multicolumn{5}{|c|}{ МГ-ЭКв $/ \Gamma$} & \\
\hline $\mathrm{F} 300 \mathrm{H}$ & 0,175 & 0,375 & 0,05 & 0,10 & 0,025 & 7,52 \\
\hline F $300 \mathrm{M}$ & 0,20 & 0,50 & 0,10 & 0,112 & 0,10 & 6,80 \\
\hline
\end{tabular}

Концентрацию сульфаниловой кислоты определяли на двулучевом спектрофотометре Uniko 4802 при длине волны $\lambda=250$ нм и толщине кварцевой кюветы $1=1 \mathrm{~cm}$.

Концентрацию меди определяли фотометрическим методом. В растворах смеси сульфаниловой кислоты и сульфата меди на 1 ммоль СК приходилось 31,4 ммоль $\mathrm{CuSO}_{4}$.

Извлечение из воды целевых соединений проводили в статических условиях на немодифицированном и модифицированном сорбентах как из индивидуальных растворов, так и из смесей исследуемых веществ.
Результаты и обсуждение. На рисунке 1 представлены изотермы адсорбции сульфаниловой кислоты на F 300 Н и F 300 М из растворов без $\mathrm{CuSO}_{4}$ и в присутствии соли меди, на рисунке 2 - изотермы сорбции меди на $\mathrm{F} 300 \mathrm{H}$ и $\mathrm{F} 300 \mathrm{M}$ из растворов $\mathrm{CuSO}_{4}$ без СК и в присутствии сульфаниловой кислоты.

Обработка представленных экспериментальных данных была проведена в соответствии с моделями Лэнгмюра и Фрейндлиха. Результаты обработки представлены в таблицах 4,5 .

Таблица 4 - Сорбция сульфаниловой кислоты

\begin{tabular}{|l|l|l|c|c|c|c|}
\hline \multirow{2}{*}{\multicolumn{1}{|c|}{ Система }} & \multicolumn{3}{|c|}{ Модель Лэнгмюра } & \multicolumn{3}{c|}{ Модель Фрейндлиха } \\
\cline { 2 - 7 } & $\mathrm{a}_{\infty}$, моль/Г (мг/г) & \multicolumn{1}{c|}{$\mathrm{K}_{\mathrm{L}}$} & $\mathrm{R}^{2}$ & $\mathrm{~K}_{\mathrm{F}}$ & $1 / \mathrm{n}$ & $\mathrm{R}^{2}$ \\
\hline F 300 H & $1,14(197,4)$ & 0,41 & 0,99 & 0,55 & 0,19 & 0,82 \\
\hline F 300 M & $1,81(313,5)$ & 0,25 & 0,97 & 0,45 & 0,35 & 0,99 \\
\hline F 300 H + Cu ${ }^{2+}$ & $1,54(266,7)$ & 0,51 & 0,99 & 0,56 & 0,26 & 0,88 \\
\hline F 300 M $+\mathrm{Cu}^{2+}$ & $0,59(102,2)$ & 2,21 & 0,99 & 0,36 & 0,17 & 0,89 \\
\hline
\end{tabular}




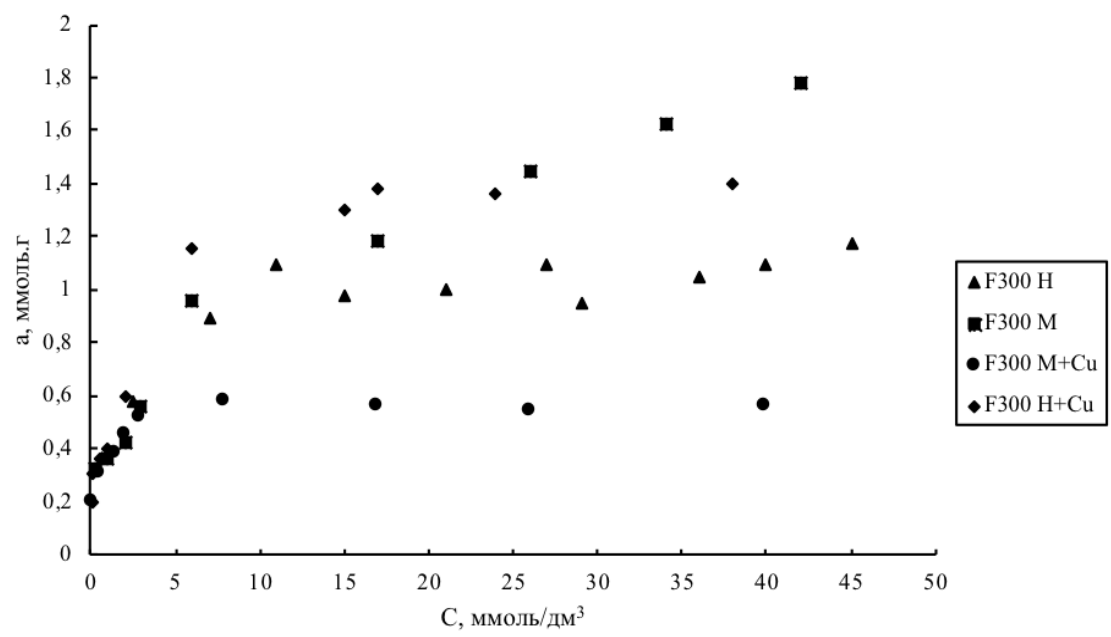

Рисунок 1 - Изотермы адсорбции сульфаниловой кислоты на F 300 Н и F 300 М из растворов без $\mathrm{CuSO}_{4}$ и в присутствии соли меди

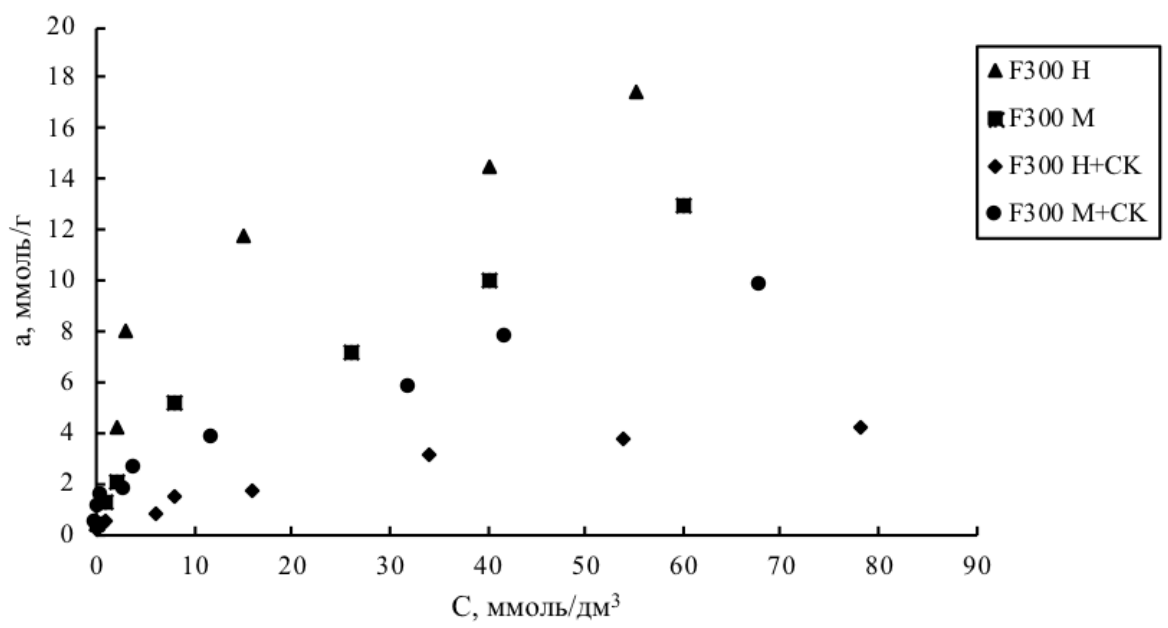

Рисунок 2 - Изотермы адсорбции меди на F 300 Н и F 300 M из растворов $\mathrm{CuSO}_{4}$ без СК и в присутствии сульфаниловой кислоты

Таблица 5 - Сорбция меди

\begin{tabular}{|l|l|c|c|c|c|c|}
\hline \multirow{2}{*}{ Система } & \multicolumn{3}{|c|}{ Модель Лэнгмюра } & \multicolumn{3}{c|}{ Модель Фрейндлиха } \\
\cline { 2 - 8 } & $\begin{array}{c}\mathrm{a}_{\infty}, \text { мг-экв/г } \\
(\mathrm{M \Gamma} / \Gamma)\end{array}$ & $\mathrm{K}_{\mathrm{L}}$ & $\mathrm{R}^{2}$ & $\mathrm{~K}_{\mathrm{F}}$ & $1 / \mathrm{n}$ & $\mathrm{R}^{2}$ \\
\hline F 300 H & $0,56(18,4)$ & 0,12 & 0,99 & 1,74 & 0,64 & 0,91 \\
\hline F 300 M & $0,47(14,9)$ & 0,06 & 0,91 & 1,17 & 0,58 & 0,92 \\
\hline F 300 H + CK & $0,21(6,7)$ & 0,03 & 0,92 & 0,30 & 0,66 & 0,98 \\
\hline F 300 M + CK & $0,34(10,7)$ & 0,08 & 0,91 & 1,03 & 0,53 & 0,99 \\
\hline
\end{tabular}

В таблицах 4, 5 приведены параметры рассмотренных моделей и изменение величины предельной удельной адсорбции $\mathrm{a}_{\infty}$ в зависимости от типа сорбента и числа компонентов в растворе. Как видно из значений коэффициентов детерминации (среднеквадратичного отклонения) $\mathrm{R}^{2}$, обе модели достаточно точно описывают экспериментальные изотермы.
Из таблиц 4, 5 видно, что модификация поверхности F 300 М приводит к существенному повышению величины $\mathrm{a}_{\infty}$ сульфаниловой кислоты при отсутствии меди (на $59 \%$ ) и снижение ее при наличии меди (на $\sim 48 \%$ ). На немодифицированном сорбенте наличие $\mathrm{Cu}^{2+}$ повышает адсорбцию СК на $35 \%$. В случае сорбции $\mathrm{Cu}^{2+}$ как модификация поверхнос-

() И. В. Косогина, Н. А. Клименко, Л. А. Савчина, С. А. Кирий, И. М. Астрелин, Е. А. Самсони-Тодорова, 2019 DOI: $10.24025 / 2306-4412.3 .2019 .178235$ 
ти, так и наличие в растворе СК приводит к снижению величины $\mathrm{a}_{\infty}$ на $19 \%$ и $64 \%$ соответственно.

Для объяснения наблюдаемых явлений целесообразно принять во внимание изменение величин рН в растворах исследуемых систем в различных условиях. Эффективность сорбции СК и меди на модифицированном и немодифицированном сорбентах в значительной мере зависит от величины рН системы, которая связана со степенью диссоциации функциональных групп СК. Характеристические свойства кислот и оснований зависят от донорного или акцепторного характера молекул, количественной мерой которого по отношению к растворителю, принятому за ве- щество сравнения, является значение константы диссоциации. Диссоциация кислот является, таким образом, источником водородных ионов в растворе. В литературе для сульфаниловой кислоты обычно приводится лишь одно значение константы ионизации, соответствующее ионизации $\mathrm{HSO}_{3}$-группы, которая равна 7,6 $10^{-4}$, а в области низких значений $\mathrm{pH}$ наблюдается появление катионов сульфаниловой кислоты в связи с ионизацией $\mathrm{NH}_{2}$ группы. Значение $\mathrm{pK}_{\text {и }}{ }^{\mathrm{a}} \mathrm{NH}_{2}$-группы сульфаниловой кислоты в среднем равно 0,7士0,2.

В таблице 6 представлены данные об изменении величины $\mathrm{pH}$ исследованных водных систем, включающих $\mathrm{CK}, \mathrm{CuSO}_{4}$ и АУ.

Таблица 6 - Изменение величины рН в исследованных многокомпонентных водных системах

\begin{tabular}{|c|c|}
\hline Система & Величина $\mathrm{pH}$ \\
\hline Дистиллированная вода & 6,0 \\
\hline Раствор СК в дистиллированной воде $\left(220\right.$ мг/дм $\left.{ }^{3}\right)$ & 2,86 \\
\hline Раствор $\mathrm{CuSO}_{4}$ в дистиллированной воде $(7$ мг/дм³ $)$ & 6,41 \\
\hline Раствор СК + $\mathrm{CuSO}_{4}$ & 2,90 \\
\hline Дистиллированная вода + F 300 M & 5,34 \\
\hline Раствор СК + F $300 \mathrm{M}$ & 7,93 \\
\hline Раствор $\mathrm{CuSO}_{4}+\mathrm{F} 300 \mathrm{M}$ & 4,85 \\
\hline Раствор CK $+\mathrm{CuSO}_{4}+\mathrm{F} 300 \mathrm{M}$ & 2,95 \\
\hline
\end{tabular}

При величине $\mathrm{pH}$ 2,86 в растворе сульфаниловой кислоты обусловлено степень диссоциации сульфогруппы в молекуле СК, которая составляет $50 \%$.

В системе раствор СК-АУ повышение $\mathrm{pH}$ раствора обусловлено взаимодействием катионных функциональных групп поверхности F 300 M с ионами СК по сульфогруппе. В смешанном растворе $\mathrm{CK}$ и $\mathrm{CuSO}_{4}$ при низких значениях $\mathrm{pH}$ имеет место, вероятнее всего, комплексообразование ионов меди с молекулой СК по группе - $\mathrm{NH}_{2}$, принимая во внимание значительное превышение содержания меди над СК.

При введении в раствор $\mathrm{CuSO}_{4}$ сорбента pH среды снижается вследствие двух причин: 1) раствор соли слабого основания и сильной кислоты имеет кислую реакцию по причине ее гидролиза; 2) введение в дистиллированную воду сорбента также снижает величину pH (таблица 6).

C учетом вышеизложенного рассмотрим влияние компонентов исследуемых систем на эффективность раздельного и совместного извлечения СК и ионов меди. Суще- ственное увеличение величины $\mathrm{a}_{\infty}$ сульфаниловой кислоты на модифицированном АУ обусловлено усилением электростатического взаимодействия в адсорбционном слое. Как видно из таблицы 3 , рН точки нулевого заряда угля F 300 М равны 6,8. В растворе с сульфаниловой кислотой в присутствии F 300 М величина $\mathrm{pH}$ практически соответствует точке нулевого заряда, что обусловливает снижение вклада электростатического взаимодействия и бо́льшей доступности поверхности сорбента для физической адсорбции СК.

При адсорбции СК в присутствии меди на немодифицированном F 300 может иметь место конкуренция за активные отрицательно заряженные центры сорбента между СК (по аминогруппе) и ионами меди, вследствие чего адсорбция СК несколько снижается. Однако при этом наблюдается существенное снижение сорбции меди (на 63,4\%) в присутствии СК. Скорее всего, это обусловлено тем, что при адсорбции СК может иметь место экранирование (перекрытие) части активных центров при ван-дер-ваальсовой адсорбции СК на сорбенте. Это предположение подтверждается

( ) И. В. Косогина, Н. А. Клименко, Л. А. Савчина, С. А. Кирий, И. М. Астрелин, Е. А. Самсони-Тодорова, 2019 DOI: $10.24025 / 2306-4412.3 .2019 .178235$ 
также снижением катионообменной емкости F 300 более, чем в два раза при введении в раствор СК - с 0,58 до 0,21 мг-экв/г.

Модифицирование F 300 Н оксидом железа приводит к некоторому снижению сорбции меди вследствие изменения зарядов активных центров поверхности. Известно, что с уменьшением $\mathrm{pH}$ на оксидах амфотерного характера, к которым относится $\mathrm{Fe}_{2} \mathrm{O}_{3}$, происходит изменение отрицательного знака заряда поверхности на положительный с переходом через ТНЗ. Сорбция в системе с модифицированным сорбентом из растворов СК и меди приводит к существенному снижению сорбции как первого, так и второго компонентов при величине $\mathrm{pH}$ раствора 2,95. Принимая во внимание амфотерный характер $\mathrm{Fe}_{2} \mathrm{O}_{3}$ и величину изоэлектрической точки модифицированного сорбента $(\sim 6,8)$, можно заключить, что в условиях $\mathrm{pH} 2,95$ имеет место перезарядка активных центров $\mathrm{Fe}_{2} \mathrm{O}_{3}$ с отрицательного на положительный. При этом адсорбция СК может происходить не только за счет дисперсионного взаимодействия с незаряженными участками поверхности, но и в результате электростатического взаимодействия аминогруппы с положительно заряженными активными центрами. Часть этих активных центров может быть занята ионами меди, снижая, таким образом, адсорбцию СК.

Представление о характере заполнения адсорбционного слоя как немодифицированного, так и модифицированного сорбента молекулами сульфаниловой кислоты можно получить при рассмотрении величин площадей, экранируемых молекулами СК при предельных значениях заполнения адсорбционного слоя -

Таблица 7 - Величины площадей, экранируемых молекулами СК, на немодифицированном и модифицированном сорбентах

\begin{tabular}{|c|c|c|c|c|}
\hline Сорбент & F 300 H & F 300 M & F 300 H + Cu & F 300 M + $\mathrm{Cu}^{2+}$ \\
\hline$\omega_{\text {эф. }}$ нм $^{2}$ & 1,84 & 1,09 & 1,37 & 3,36 \\
\hline
\end{tabular}

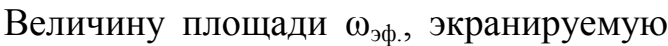
адсорбированной молекулой СК, определяли из известного соотношения:

$$
\omega_{\text {эф. }}=\mathrm{S}_{\text {эф. }} \cdot 10^{18} /\left(\mathrm{a}_{\infty} \cdot 6,023 \cdot 10^{23}\right),
$$

где $\mathrm{S}_{\text {эф. }}$ - эффективная удельная поверхность сорбента, $\mathrm{M}^{2} / \Gamma$;

$\mathrm{a}_{\infty}$ - предельная величина удельной адсорбции, соответствующая заполнению мономолекулярного слоя, моль/г;

$6,023 \cdot 10^{23}$ - число Авогадро.

Как видно из таблицы 7, на модифицированном сорбенте в присутствии $\mathrm{Cu}^{2+}$ величина площади сорбента, экранируемая сорбированной молекулой СК, в $~ 3$ раза больше, чем в системе F $300 \mathrm{M}$ - сульфаниловая кислота. Это обусловлено изменением химии поверхности и, соответственно, появлением отрицательно заряженных активных центров, что приводит, вероятно, к некоторой осцилляции адсорбированной молекулы СК в результате электростатического отталкивания. Увеличение площади, экранируемой адсорбированной молекулой СК, в свою очередь, приводит к снижению сорбции меди, хотя и в меньшей степени, чем на немодифицированном сорбенте F 300 вследствие перекрытия некоторого количества активных отрицательно заряженных центров.
Из данных, приведенных в таблицах 4, 5 , видно, что наличие в растворе сульфаниловой кислоты - как на F $300 \mathrm{H}$, так и на F 300 M - приводит к уменьшению сорбируемости меди. Это свидетельствует об отсутствии комплексообразования в адсорбционном слое, так как в противном случае наличие СК могло обусловить сверхэквивалентную сорбцию ионов меди при связывании их в поверхностный комплекс.

Выводы. Таким образом, модифицирование активированного угля $\mathrm{F} 300$ оксидами железа приводит к существенному увеличению адсорбционной емкости сорбента по сульфаниловой кислоте. Хотя величина $\mathrm{a}_{\infty}$ по СК снижается в присутствии ионов $\mathrm{Cu}^{2+}$, тем не менее, сохраняется достаточно высокая степень сорбции по меди на модифицированном сорбенте по сравнению с немодифицированным. Принимая во внимание сложный характер физико-химических взаимодействий в системе, содержащей сульфаниловую кислоту с кислотной и основной группами, и конкурирующее влияние при определенных условиях, можно ожидать, что модифицирование активированного угля раствором хлоридов металлов, полученных кислотной активацией отходов глиноземных производств с последующим переводом их в оксидную форму, явля-

() И. В. Косогина, Н. А. Клименко, Л. А. Савчина, С. А. Кирий, И. М. Астрелин, Е. А. Самсони-Тодорова, 2019 DOI: $10.24025 / 2306-4412.3 .2019 .178235$ 
ется перспективным направлением при очистке воды, содержащей как органические соединения, так и ионы цветных металлов.

\section{Список литературы / References}

[1] Li Qimeng, et al., "Competition and enhancement effect in coremoval of atenolol and cooper be an easily regenerative magnetic cation exchange resin", Chemosphere, vol. 179, pp. 1-9, 2017.

[2] C.-G. Lee, et al., "Removal of copper, nickel and chromium mixtures from metal plating wastewater by adsorption with modified carbon foam", Chemosphere, vol. 166, pp. 203-211, 2017.

[3] M. A. Yan, et al., "A bifunctional adsorbent with high area and cation exchange property for synergistic removal of tetracycline and $\mathrm{Cu}^{2+"}$, Chemical Engineering Journal, vol. 258, pp. 26-33, 2014.

[4] Chen Ling, Qiang Liu Fu, Xu Chao, Chen Tai-Peng, and $\mathrm{Li}$ Ai-Min, "An integrative technique based on synergistic coremoval an sequential recovery of copper and tetracycline with dual-functional chelating resin: roles of amine and carboxyl groups", Applied Materials and Interfaces, vol. 5, pp. 11808-11817, 2013.

[5] Chen Taipeng, et al., "Insight into highly efficient coremoval of copper and pnitrophenol by a newly synthesized polyamine chelating resin from aqueous media: competition and enhancement effect upon site recognition", Environmental Science and Technology, vol. 47, pp. 13652-13660, 2013.

[6] Han Jiaxi, Du Zhongjie, Zou Wei, Li Hangquan, Zhang Chen, "In-situ improved phenol adsorption at ions-enrichment interface of porous adsorbent for simultaneous removal of copper and phenol", Chemical Engineering Journal, vol. 262, pp. 571-578, 2015.

[7] Fu Linchun, et al., "High-efficient technique to simultaneous removal of $\mathrm{Cu}$ (II), Ni (II) and tannic acid with magnetic resins: complex mechanism behind integrative application", Chemical Engineering Journal, vol. 263, pp. 83-91, 2015.
[8] D. P. Siriwardena, M. Crimi, T. M. Holsen, C. Bellona, C. Divine, and E. Dickenson, "Changes in adsorption behavior of perfluorooctanoic acid and perfluorohexanesulfonic acid through chemically-facilitated surface modification of granular activated carbon", Environmental Engineering Science, vol. 36, pp. 453-465, 2019.

[9] E. Kan, and S. G. Huling, "Effects of temperature and acidic pre-treatment on fentondriven oxidation of mtbe-spent granular activated carbon", Environmental Science \& Technology, vol. 43, pp. 1493-1499, 2009.

[10] O. V. Zabneva, S. K. Smolin, N. A. Klimenko, O. G. Shvidenko, S. V. Grechanik, and A. V. Sinel'nikova, "Structural and sorption properties of activated carbon modified with iron oxides", Journal of Water Chemistry and Technology, vol. 34 (6), pp. 264-270, 2012.

[11] A. Bhatnagar, W. Hogland, M. Marques, and M. Sillanpää, "An overview of the modification methods of activated carbon for its water treatment applications", Chemical Engineering Journal, vol. 219, pp.499-511, 2013.

[12] Li Yiran, Zhang Jian, and Liu Hai, "In-situ modification of activated carbon with ethylenediaminetetraacetic acid disodium salt during phosphoric acid activation for enhancement of nickel removal", Powder Technology, vol. 325, pp. 113-120, 2018.

[13] S. Amerkhanova, R. Shyapov, and Aitolkyn Uali, "The active carbon modified by industrial wastes in process of sorption concentration of toxic organic compounds and heavy metals ions", Colloid and Surface A: Physico-chemical and Engineering Aspects, vol. 532, pp. 36-40, 2017.

[14] O. V. Zabneva, S. K. Smolin, N. A. Klimenko, O. G. Shvidenko, S. V. Grechanik, and A. V. Sinel'nikova, "Structural and sorption properties of activated carbon modified with iron oxides", Journal of Water Chemistry and Technology, vol. 34 (6), pp. 264-270, 2012.

[15] M. N. Khan, and A. Sarwar, "Determination of the point zero charge of natural and processed adsorbents", Surface Review and Letters, vol. 14, pp. 461-469, 2007. 


\author{
I. V. Kosogina ${ }^{1}$, N. A. Klymenko ${ }^{2}$, L. A. Savchyna ${ }^{2}$, \\ S. A. Kyrii ${ }^{1}$, I. M. Astrelin ${ }^{1}$, E. A. Samsoni-Todorova ${ }^{2}$ \\ ${ }^{1}$ National Technical University of Ukraine "Igor Sikorsky Kyiv Polytechnic Institute", \\ Peremohy ave., 37, Kyiv, 03056, Ukraine \\ ${ }^{2}$ A. V. Dumanskiy Water Colloid Chemistry Institute, \\ Akademika Vernadskogo blvd, 42, Kyiv, 03142, Ukraine

\section{SORPTION OF SULFANILIC ACID AND COPPER IONS BY ACTIVATED} \\ CARBON MODIFIED WITH METAL OXIDES
}

The possibility of using activated carbon brand Filtrasorb 300 modified with metal oxides $(F 300 \mathrm{M})$ in comparison with unmodified $(\mathrm{F} 300 \mathrm{H})$ for the simultaneous extraction of organic compounds and copper ions from water has been established. A solution of metal chloride obtained by acidthermal activation of waste from alumina production "red mud" is used as a modifier. The process of sulfanilic acid and copper ions sorption by modified and unmodified activated carbon Filtrasorb 300 (AC F300) is investigated. The structural-sorption characteristics of the studied materials, such as: static exchange cationic and anionic capacities and the number of surface groups (carboxyl, lactone, phenolic), are determined. Positive effect of activated carbon modification by metal oxides that has been obtained as a result of acid-thermal treatment of "red mud" is shown. The presence of negatively charged active centers on modified activated carbon surface makes it possible to increase by $59 \%$ the value of sulfanilic acid adsorption due to the interaction of the material surface with $-\mathrm{NH}_{2}$ group of the acid with the absence of copper ions in the solution, which is $24 \%$ more than AB F300. Simultaneous presence of copper ions and sulfanilic acid reduces their adsorption on the modified sorbent as a result of blocking the active groups and reducing the electrostatic interaction. Taking into account the complex nature of physical-chemical interactions in a system that contains sulfanilic acid with acidic and basic groups, and the competing effect under certain conditions, it can be expected that the modification of activated carbon with a metal chloride solution (obtained by acidic activation of alumina production wastes with their subsequent conversion to oxide form), is a promising direction in water treatment in case of containing both organic compounds and non-ferrous metal ions.

Keywords: sorption, modified activated carbon, structural-sorption characteristics, sulfanilic acid, copper ions, water treatment.

\title{
І. В. Косогіна, Н. А. Клименко, С. О. Кирій, І. М. Астрелін, О. О. Самсоні-Тодорова СОРБЦІЯ СУЛЬФАНІЛОВОЇ КИСЛОТИ І ЙОНІВ МІДІ АКТИВОВАНИМ ВУГІЛЛЯМ, МОДИФІКОВАНИМ ОКСИДАМИ МЕТАЛІВ
}

Встановлено можливість використання активованого вугілля марки Filtrasorb 300, модифiкованого оксидами металів (F 300 M), порівняно з немодифікованим оксидами металів вугіллям (F 300 H), для одночасного вилучення з води різноманітних органічних сполук та йонів міді. Як модифікатор використовується розчин хлориду металу, отриманий при кислотно-термічній активаиії відходів виробництва глинозему «червона грязь». Досліджено процес сорбиї сульфанілової кислоти (СК) та йонів міді модифікованим та немодифікованим активованим вугіллям Фільтрасорб 300 (АC F 300). Визначено структурно-сорбиійні характеристики досліджуваних матеріалів, такі як: катіонні та аніонні ємності статичного обміну та кількість поверхневих груп (карбоксил, лактон, фенол). Показано позитивний ефект модифікаиії активованого вугілля оксидами металів, отриманий в результаті кислотно-термічної обробки «червоної грязі». Наявність негативно заряджених активних центрів на модифікованій поверхні активованого вугілля дозволяє на $59 \%$ збільшити значення адсорбиії сульфанілової кислоти за рахунок взаємодї поверхні матеріалу з групою - $\mathrm{NH}_{2}$ кислоти за відсутності йонів міді в розчині, щэо на $24 \%$ більще, ніж АB F300. Розглянуто вплив компонентів досліджуваних систем на ефективність роздільного і спільного вилучення СК $і$ йонів міді. Одночасна присутність йонів міді та сульфанілової кислоти знижує їх адсорбиію на модифікованому сорбенті внаслідок блокування активних груп та зменшення електростатичної взаємодії. Враховуючи складний характер фізико-хімічних взаємодій у системі, щэо містить сульфанілову кислоту з кислими та основними групами, а також конкуруючий ефект за певних умов, можна очікувати, щзо модифікачія активованого вугілля розчином хлориду металу (отримана кислотна активачія відходів виробнищтва глинозему з подальшим перетворенням їх у оксидну форму) є перспективним напрямком в очищенні води у разі вмісту як органічних сполук, так і йонів кольорових металів.

Ключові слова: сорбція, модифіковане активоване вугілля, структурно-сорбиійні характеристики, сульфанілова кислота, йони міді, водоочищення.

Стаття надійшла 15.08.2019

Прийнято 02.09.2019

(c) И. В. Косогина, Н. А. Клименко, Л. А. Савчина, С. А. Кирий, И. М. Астрелин, Е. А. Самсони-Тодорова, 2019 DOI: $10.24025 / 2306-4412.3 .2019 .178235$ 